\title{
Review
}

\section{NK cells at the interface between innate and adaptive immunity}

\author{
A Moretta ${ }^{*, 1,2}$, E Marcenaro ${ }^{1}$, S Parolini ${ }^{3}$, G Ferlazzo $^{4}$ and L Moretta ${ }^{1,2,5}$
}

In recent years a novel concept has emerged indicating that the actual role of natural killer (NK) cells is not confined to the destruction of virus-infected cells or tumors. Indeed, different NK subsets exist that display major functional differences in their cytolytic activity, cytokine production and homing capabilities. In particular, CD56 ${ }^{\text {high }}$ CD16 ${ }^{-}$NK cells that largely predominate in lymph nodes, have little cytolytic activity but release high levels of cytokines whereas $\mathrm{CD}_{56}{ }^{\text {low }} \mathrm{CD} 16^{+} \mathrm{NK}$ cells that predominate in peripheral blood and inflamed tissues, display lower cytokine production, but potent cytotoxicity. The latter is characterized by granule polarization and exocytosis of various proteins including perforin and granzymes that mediate target cell killing. The recruitment of $\mathrm{CD} 56^{\text {low }} \mathrm{CD} 16^{+} \mathrm{NK}$ cells into inflamed peripheral tissues is orchestrated by various chemochines including the newly identified Chemerin. At these sites, NK cells, upon engagement of different triggering receptors become activated and upregulate their cytokine production and cytotoxicity after interaction with myeloid dendritic cells (DCs). Importantly, during this interaction NK cells also mediate the 'editing' of DCs undergoing maturation. This process appears to play a crucial role in shaping both innate and adaptive immune responses. Indeed, only DCs undergoing this NK-mediated quality control would become fully mature and capable of inducing priming of protective Th1 responses.

Cell Death and Differentiation (2008) 15, 226-233; doi:10.1038/sj.cdd.4402170; published online 1 June 2007

Natural killer (NK) cells function as important sentinels of the immune system, working as primary responders and alerting the host to the presence of infectious organisms. These cells represent a subset of cytotoxic lymphocytes that is able to recognize and lyse tumor cells and virus-infected cells without previous sensitization. ${ }^{1,2} \mathrm{NK}$ cells derive from the bone marrow, circulate in the blood and become activated by cytokines, pathogen-derived substances or upon encountering target cells that express ligands for NK cell receptors. ${ }^{3} \mathrm{NK}$ cell receptors are encoded in the germ line and do not undergo somatic recombination like $B$ - and T-cell antigen receptors; ${ }^{4}$ it is the balance of signals from activating and inhibitory receptors that determines the outcome of NK cell function. ${ }^{5}$ Some inhibitory receptors recognize MHC class I, which is present on virtually all healthy cells, and prevent NK cell attack against these cells. ${ }^{6-9}$ Loss of $\mathrm{MHC}$ class I from cells owing to infection or tumor transformation can lead to NK cell activation, as proposed by the 'missing self hypothesis', ${ }^{10}$ provided that an activating receptor is engaged. The activating NK receptors bind to host-derived or pathogen-encoded ligands that are upregulated on 'stressed' or infected cells. Upon activation, NK cells directly lyse target cells by exocytosis of perforin and granzymes. Moreover, NK cells also display regulatory capabilities mediated by various cytokines released upon engagement of different triggering NK receptors or upon signaling by other cytokines. This is particularly relevant during the early phases of inflammatory responses. ${ }^{11}$ Several data have recently highlighted the role of the interactions between NK cells and other cells of the innate immune system that occur during the early phases of acute inflammation, secondary to infection. Various studies were focused on the crosstalk between NK cells and monocyte-derived dendritic cells (DCs) ${ }^{12-21}$ and more recently on the involvement of plasmacytoid dendritic cells (PDC), mast cells, basophils, eosinophils, and neutrophils. ${ }^{22-24}$ In view of these observations it appears that a complicated network of interactions ${ }^{25}$ can take place after the recruitment of these different cells to inflammatory sites in response to tissue damage resulting from invasion by pathogens (or tumor cells).

In this review, we will highlight recent studies on the mechanisms by which NK cells are recruited to inflamed tissues and respond to pathogens, and will underscore the unique role of NK cells in both innate and adaptive immunity.

\footnotetext{
${ }^{1}$ Dipartimento di Medicina Sperimentale, Università degli Studi di Genova, Via L.B. Alberti 2, Italy; ${ }^{2}$ Centro di Eccellenza per le Ricerche Biomediche, Università degli Studi di Genova, V.le Benedetto XV, Genova, Italy; ${ }^{3}$ Dipartimento di Scienze Biomediche e Biotecnologie, Università di Brescia, Viale Europa, 11, Brescia, Italy; ${ }^{4}$ Dipartimento di Patologia Umana, Università di Messina, Italy and ${ }^{5}$ Istituto Giannina Gaslini, L.go G. Gaslini 5, 16148 Genova, Italy

*Corresponding author: A Moretta, Dipartimento di Medicina Sperimentale, Sezione di Istologia, Via G.B. Marsano 10, 16132 Genova, Italy. Tel: + 39 010 3537868 ; Fax: + 39010 3537576; E-mail: alemoret@unige.it

Keywords: NK lymphocytes; cytokine release; cytotoxicity; activating receptors; dendritic cells

Abbreviations: NCR, natural cytotoxicity receptors; KIR, Killer Ig-like Receptors; poly (I.C), polyinosinic-polycytidylic acid; TNF- $\alpha$, tumor necrosis factor $\alpha$; GM-CSF, granulocyte/macrophage colony-stimulating factor; LPS, lipopolysaccharide; Ag, antigen; TLR, toll like receptors; DC, dendritic cells; iDC, immature DC; HA, hemagglutinin; ULBP, UL16-binding protein

Received 14.3.07; revised 24.4.07; accepted 26.4.07; Edited by SJ Martin; published online 01.6.07
} 


\section{Multiple Integrated Signals Control Degranulation and Killing by NK Cells}

Several structurally distinct activation receptors have been implicated in NK cell cytotoxicity, a complex process that involves adhesion, synapse formation, and granule polarization and exocytosis. ${ }^{26,27}$ Besides expression of several receptors that mediate natural cytotoxicity, ${ }^{5}$ expression of CD16 on a majority of NK cells renders them strong mediators of antibody-dependent cellular cytotoxicity (ADCC) against IgG coated target cells. ${ }^{28}$ However because of the multiplicity of receptor/ligand interactions between NK cells and target cells, it has been difficult to assign specific functions to individual receptors. In NK cells, lytic granules are secretory lysosomes that contain a dense core, including various proteins that are involved in cytotoxic function such as perforin and granzymes. The combined function of these proteins leads to the generation of pores on the plasma membrane and activation of the caspase cascade after cleavage of caspase-3. The latter activates caspaseactivated DNase that degrades DNA, thus inducing apoptosis of target cells.

The core of lytic granules is surrounded by a lipid bilayer that contains Fas ligand and lysosomal-associated membrane glycoproteins (LAMPs). ${ }^{29}$ Degranulation by NK cells results in depletion of intracellular perforin and LAMP-1 (CD107a) appearance at the cell surface. ${ }^{30}$ Recently, Long and co-workers ${ }^{31-33}$ demonstrated that cytolytic granule polarization and degranulation are two steps in NK cellmediated cytotoxicity that are controlled separately by signals emanating from distinct receptors. Thus, engagement of integrin LFA-1 by its ligand, ICAM-1, signals for polarization; whereas CD16 engagement by its ligand, IgG Fc, triggers degranulation. Neither polarization nor degranulation is sufficient for efficient target cell lysis; however, coengagement of CD16 and of LFA-1 results in strong cytotoxicity. The signal from LFA-1 for polarization and the signal from CD16 for degranulation appear to be separate, because LFA-1 provided no enhancement of degranulation, and CD16 provided only a small increase in polarization. The degranulation induced by CD16 engagement suggested that other ITAM-associated receptors, such as the natural cytotoxicity receptors NKp46, NKp44, and $\mathrm{NKp30},{ }^{34}$ also might be sufficient to induce degranulation. However, at least in resting NK cells, the only activating receptor inducing efficient cytotoxicity appears represented by CD16. ${ }^{32,33}$ On the other hand, in activated NK cells the responsiveness of the natural cytotoxicity receptors is strongly upregulated; in line with this concept we observed that cross-linking of these receptors by plastic-bound specific mAbs was sufficient to induce CD107a exposure at the NK cell surface (Figure 1) and a sharp decrement of the amount of intracellular perforin (not shown).

\section{NK Cell Migration into Inflamed Tissues}

During inflammation, viral infection and tumor growth, NK cells are rapidly recruited from the blood into injured tissues. ${ }^{18-21}$ NK cell recruitment is governed by integrated signals, which include adhesion molecules and chemotactic factors. CD56 ${ }^{\text {low }} \mathrm{CD} 16^{+} \mathrm{NK}$ cells express both $\beta 1$ and $\beta 2$ integrins, as well as the ligands for $\mathrm{E}$ - and $\mathrm{P}$-selectins. In addition to these molecules, CD56 ${ }^{\text {high }}$ NK cells also express high levels of L-selectin, a pivotal molecule for the interaction with lymph node high endothelial venules. A crucial role in the transendothelial migration process of different leukocyte types including NK cells is also played by the DNAM-1 receptor expressed on human NK cells. ${ }^{35}$ Its ligands, PVR
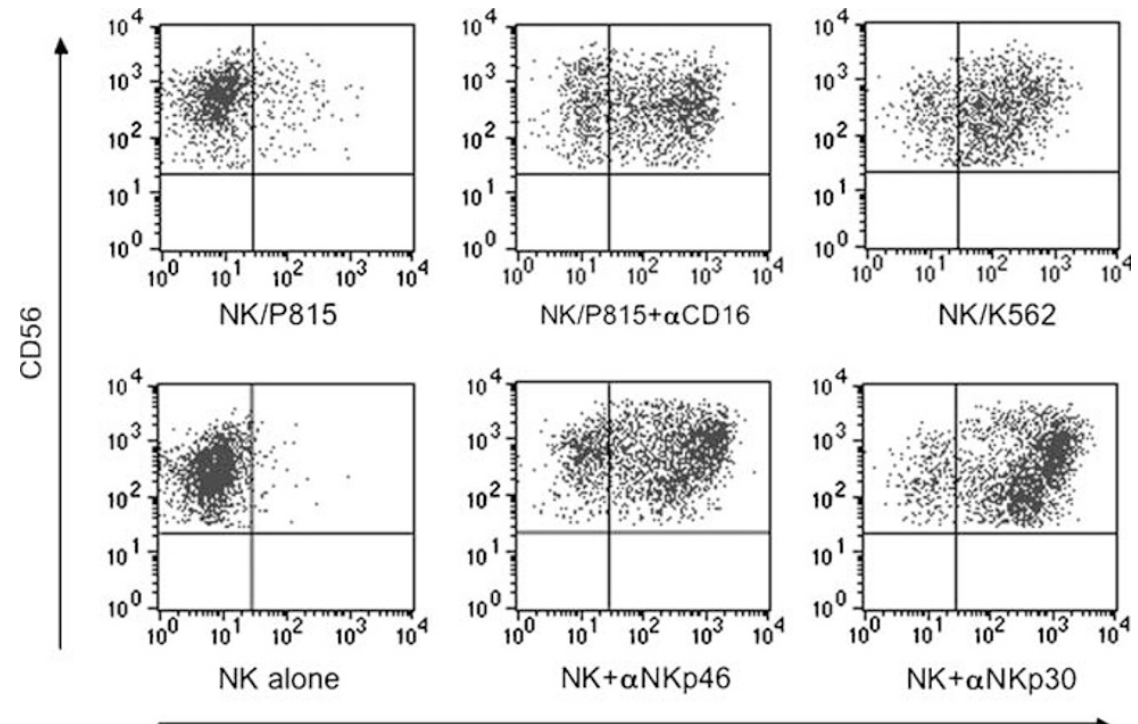

CD107a

Figure 1 Induction of CD107a expression on the surface of IL2-activated human natural killer (NK) cells. NK cells that had been cultured overnight in the presence of exogenous IL2 were incubated for $3 \mathrm{~h}$ at $37^{\circ} \mathrm{C}$ in the absence or in the presence of various stimuli, including P815 cell line, P815 and anti-CD16 mAb, K562 cell line, platebound anti-NKp46 or anti-NKp30 mAbs. PE-anti-human CD107a mAb lysosomal-associated membrane glycoprotein-1 (LAMP-1) was included during the incubation. Thereafter, cells were stained with PC5-conjugated anti-CD56 mAb and PE-anti-CD107a mAb 
and Nectin-2, are present at the cell junctions on primary vascular endothelial cells and mAb against DNAM-1 or PVR (CD155) inhibited the transendothelial NK cell migration. The DNAM-1/PVR interaction appears to play an essential role during the diapedesis step, since, in the presence of anti DNAM-1 or anti-PVR mAb, migrating leukocytes were arrested at the apical surface of the endothelium over intercellular junctions. ${ }^{36}$ Various soluble factors play an important role in the early events that favor the extravasation of NK cells and the subsequent induction of their priming. These include various cytokines and chemokines that are released by resident DC and other cell types including endothelial cells, macrophages, neutrophils, fibroblasts, mast cells and eosinophils during pathogen-induced inflammation in peripheral tissues. The mechanism of NK cell recruitment appears to involve chemokines such as CXCL8, CCL3 and CX3CL $1 .{ }^{18}$ Indeed most classical NK cells (CD56 ${ }^{\text {low }}$ CD16 $^{+}$) express CXCR1 and CX3CR1 while the minor CD56 ${ }^{\text {high }}$ CD16 ${ }^{-}$NK subset express CCR7. ${ }^{37-39}$ On the basis of their surface phenotype it is conceivable that $\mathrm{CD} 56^{\text {low }} \mathrm{CD} 16^{+}$cells may be mainly recruited in pathogen-invaded inflamed tissues, whereas $\mathrm{CD}_{56}{ }^{\text {high }} \mathrm{CD} 16^{-}$cells may be essentially attracted by secondary lymphoid compartments such as lymph nodes. ${ }^{18}$ Indeed, in lymph nodes, CCL21 is highly expressed in high endothelial venules (HEVs), lymphatic vessels, and stromal/interdigitating DCs (predominantly in T-cell areas), whereas CCL19 is highly expressed in mature DCs within the $T$ cell zone of para-cortex. ${ }^{40,41}$ Accordingly within normal non-inflamed lymph nodes NK cells, which are localized in the para-follicular area next to the para-cortical T-cell area, ${ }^{42,43}$ are homogeneously characterized by the CD56 ${ }^{\text {high }}$ CD94/NKG2A ${ }^{+}$surface phenotype, by low levels of cytolytic activity and by the production of high amounts of interferon (IFN) $-\gamma$. Thus these cells are very similar to the small CD56 ${ }^{\text {high }} \mathrm{CD}^{-} \mathrm{NK}$ cell subset that is found in peripheral blood. The developmental relationship between these two NK cell subsets remains controversial although a recent report demonstrated that upon exposure to interleukin IL2, IL15 or IL12 in vitro peripheral blood CD56 ${ }^{\text {high }}$ NK cells gain the typical pattern of CD56 ${ }^{\text {low }} \mathrm{NK}$ cells. ${ }^{44}$ Indeed ex-vivo analysis of human NK cells showed that CD16 and KIR expression was similar in NK cells derived from efferent lymph and PB, while the same molecules were almost absent in NK cells collected from non-reactive lymph nodes (LN), suggesting that NK cells leave the LN after KIR acquisition. In line with this concept, CD56 ${ }^{\text {low }}$ NK cells displayed shorter telomeres than CD56 ${ }^{\text {high }}$ NK cells. These data suggest that CD56 ${ }^{\text {high }}$ $\mathrm{CD}^{-} 6^{-} \mathrm{KIR}^{-}$and CD56 ${ }^{\text {low }} \mathrm{CD}^{-} 6^{+} \mathrm{KIR}^{+/-} \mathrm{NK}$ cells correspond to sequential steps of differentiation and that secondary lymphoid tissues may represent sites of NK cell development and self-tolerance acquisition.

It is important to note that the acquisition of KIR within LN does not necessarily imply that each single NK cell should undergo maturation at these sites. In this context, recent data indicated that during maturation NK cells undergo an education process based on the recognition of self-HLA class I molecules that allows the acquisition of a full functional competence. These data clearly suggest that this process must be confined to those NK cells that express at least one receptor for self-HLA class I although, even in normal individuals, some NK cells are generated that lack these receptors. Such cells, however, would not be dangerous since, in the absence of adequate education, they would not acquire functional competence. In lymph nodes, NK cells lacking inhibitory receptors for self-HLA may not exist since even before KIR acquisition they express high levels of CD94/ NKG2A (which represent a classical feature of all CD56 ${ }^{\text {high }}$ $\mathrm{CD}^{-} 6^{-} \mathrm{NK}$ cells). Thus KIR acquisition in LN appears to be confined to NK cells that have been previously subjected to the education process, ${ }^{45}$ upon recognition of HLA-E. Consequently, KIR acquisition in LN does not represent a step of NK cell maturation from immature NK precursors but rather a 'switch' from a $\mathrm{KIR}^{-}$to a $\mathrm{KIR}^{+}$phenotype.

\section{NK Cells and DCs Meet in Inflamed Tissues}

Recently, an additional chemokine has been described that is likely to play a crucial role in NK cell recruitment at inflamed sites. This is represented by Chemerin, which is a chemotactic agonist recently identified as the ligand of ChemR23, a serpentine receptor that was originally detected on the surface of mononuclear phagocytes and DCs. ${ }^{46}$

More recently, the Chemerin receptor (Figure 2) has been described on blood NK cells: indeed it was shown that ChemR23 expression marks the major CD56 ${ }^{\text {low }} \mathrm{CD}^{+}{ }^{+}$ peripheral blood NK cell subset, with no expression by CD56 ${ }^{\text {high }}$ NK cells. ${ }^{47}$ Consistent with their CD56 $^{\text {low }}$ phenotype, ChemR23 ${ }^{+}$cells express CXCR1 as well as KIRs and CD16 molecules. Importantly, Chemerin promotes the migration of NK cells and this migration is dependent on ChemR23, as based on the inhibitory effects of ChemR23 blocking antibodies. Despite the large body of evidence about the role of NK cell-DC interactions, little evidence supports the concept that this interaction indeed takes place in peripheral tissues, in vivo. ${ }^{48}$ However, analysis of the expression of ChemR23 by NK cells in pathological conditions known to be characterized by elevated tissue accumulation of DC such as oral lichen planus (OLP) showed, in addition to numerous $\mathrm{CD}_{123}{ }^{+} / \mathrm{BDCA}^{+}$and $\mathrm{DC}-\mathrm{SIGN}{ }^{+} \mathrm{DC}$, the presence of $\mathrm{CD}^{-} \mathrm{CD}^{-} 6^{+} \mathrm{NK}$ cells. Both DC subsets and NK cells expressed ChemR23 with NK cells accounting for about $25 \%$ of the total ChemR23 ${ }^{+}$cells present in each lesion. Only a fraction of ChemR23 ${ }^{+}$NK cells expressed CD69, an early activation marker, suggesting that ChemR23 was mostly expressed by recently recruited NK cells. This finding may also indicate that only a fraction of the recruited NK cell population undergoes activation at inflammatory sites. Since NK cells were found in close proximity with both plasmacytoid and myeloid $\mathrm{DC},{ }^{47}$ it is likely that this interaction will result in reciprocal cell activation. Under normal conditions, chemerin is absent in non-lymphoid peripheral tissues, including dermis and epidermis; ${ }^{46}$ on the other hand, in OLP lesions, endothelial cells lining blood vessels express chemerin. ${ }^{47}$ This finding further supports the role of chemerin in the recruitment and co-localization of NK cells and DC subsets in inflamed tissues. Altogether, the different mechanisms described above would explain how NK cells can be recruited to inflamed tissues and meet with immature DC (iDC) within a short period of time after pathogen attack. 


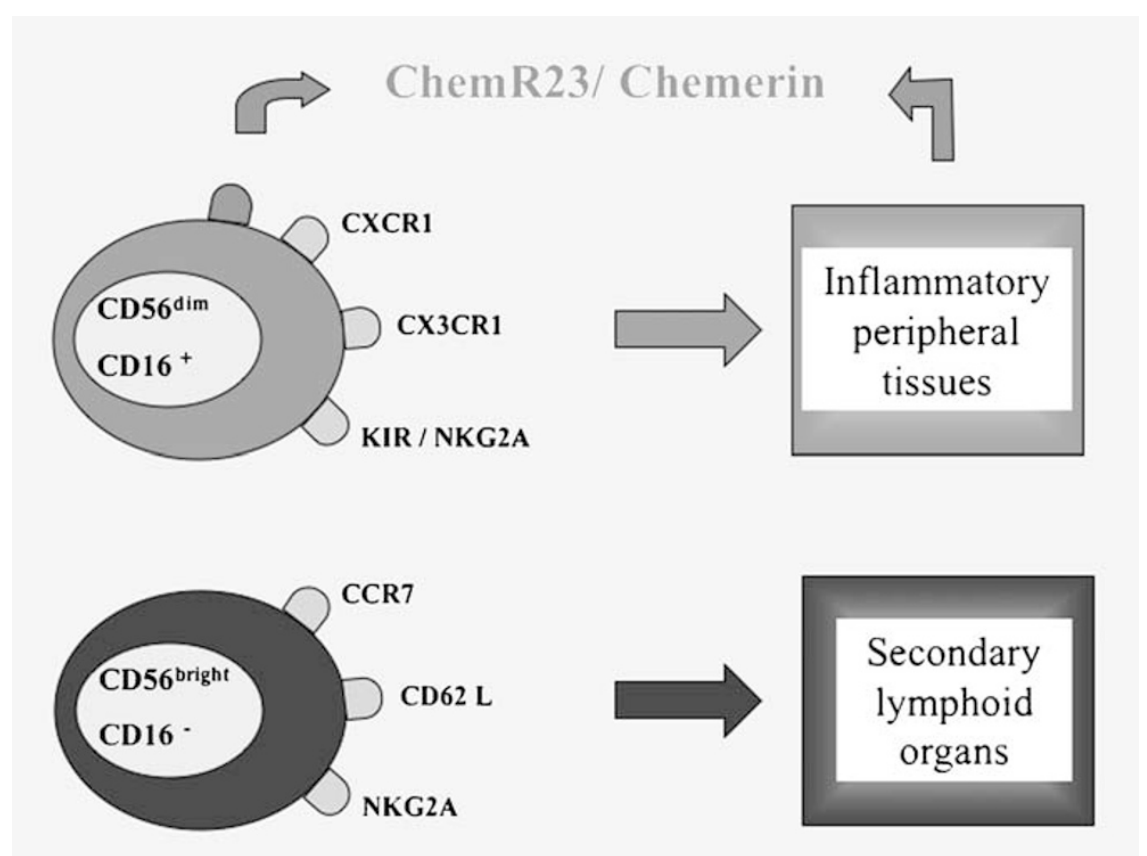

Figure 2 ChemR23 expression on natural killer (NK) cell subsets. Human natural killer cells can be divided into CD56 ${ }^{\text {low }} \mathrm{CD} 16^{+}$, killer Ig-like receptors (KIR) $+/-$and $\mathrm{CD} 56^{\text {high }} \mathrm{CD} 16^{-} \mathrm{KIR}^{-}$subsets, displaying different functions, phenotype and tissue localization. CD56 $6^{\text {low }} \mathrm{NK}$ cells dominate in peripheral blood (PB), whereas CD56 $6^{\text {high }}$ are enriched in secondary lymphoid organs. Indeed, the majority ( $\geqslant 95 \%$ ) of peripheral blood NK cells belongs to the $\mathrm{CD} 56^{\text {low }} \mathrm{CD} 16^{+}$cytolytic NK subset, that carry homing markers for inflamed peripheral sites (CXCR1 and CX3CR1) and perforin to rapidly mediate cytotoxicity. It has also been shown that CD56 $6^{\text {low }} \mathrm{CD} 16^{+}$but not $\mathrm{CD} 56^{\text {high }} \mathrm{CD} 16^{-}$ NK cells express the recently identified ChemR23 receptor for the chemotactic agent Chemerin, which is a potent inducer of NK cell recruitment into inflamed peripheral tissues. On the other hand, $\mathrm{CD} 56^{\text {high }} \mathrm{CD} 16^{-} \mathrm{NK}$ cells, unlike $\mathrm{CD} 56^{\text {low }} \mathrm{CD} 16^{+}$, express the receptor for the stem cell factor (c-kit or CD117), the $\alpha$-chain of IL7 receptor and homing markers for secondary lymphoid organs, namely CCR7, CD62L and CXCR3

\section{Activation of NK Cells in Peripheral Tissues}

After being recruited into inflamed tissues, NK cells can interact with other cell types of the innate immune system. ${ }^{24,25}$ These interactions can modulate NK cell functions as a result of mechanisms of cell to cell contact (favoring receptor/ligand interactions) and of the activity of soluble factors. For example, a close cell to cell contact is required in the case of NK-monocyte-derived DC interactions. ${ }^{18-21}$ During such NK-DC contact, DCs undergoing maturation after antigen uptake release cytokines that can greatly influence the functional behavior of NK cells. For example, DC-derived IL12 is crucial not only for inducing NK cells to release interferon (IFN)- $\gamma$ but also, for enhancing NK-cell cytotoxicity. ${ }^{49}$ The formation of 'stimulatory synapses' between NK and DC has been shown to promote a polarized secretion of IL12 (present in DC preassembled stores) toward NK cells. ${ }^{50}$ On the other hand, enhancement of NK cytotoxicity can also be induced by type I IFN abundantly secreted by PDC $^{51}$ or mastocytes. $^{52}$ Therefore, the upregulation of NK-mediated killing is greatly influenced by the type of cytokines released by bystander cells during innate immune responses. In turn, the apoptotic/necrotic material or heat-shock proteins that are generated as a result of the NK-mediated killing of tumors or virus-infected cells can modulate the function of DC or other bystander cells. ${ }^{18}$ It has been shown that NK cells kill certain virus-infected or tumor cells expressing low levels of MHC class I molecules and subsequently can prime DCs to promote Th1 responses ${ }^{53}$ and highly protective CD8
T-cell-mediated memory responses. ${ }^{54}$ Moreover, NK-DC interactions can induce primary tumor rejection and long-term CTL memory, apparently bypassing the requirement for helper $\mathrm{CD}^{+}{ }^{+} \mathrm{T}_{\text {cells. }}{ }^{55}$

Another mechanism by which recruited NK cells can become activated and upregulate their cytolytic activity is based on the usage of Toll-like receptors. It has been shown that circulating as well as in vitro activated human NK cells express these receptors including TLR3 and TLR9, that enable them to respond both to viral and bacterial products. ${ }^{56}$ For example, the simultaneous engagement of TLR3 on both NK cells and monocyte-derived DC appears to be sufficient to initiate a series of events, characteristics of the early phases of innate immune responses. Thus, exposure of NK and myeloid DC to dsRNA (a classical TLR3 ligand) results in IL12 secretion by DCs and in NK cell activation, as revealed by the surface expression of CD69 and CD25. In addition, TLRstimulated NK cells, in the presence of IL12, release cytokines including IFN- $\gamma$ and tumor necrosis factor (TNF)- $\alpha$ and acquire a higher cytolytic activity against tumor target cells.

\section{NK Cell-Mediated Killing of DC}

Once activated, NK cells recruited to sites of inflammation, acquire the capability of killing immature myeloid DCs. ${ }^{18-21}$ This effect is due to the fact that immature DCs typically underexpress HLA-class I molecules that would protect from NK-mediated lysis. On the other hand, DCs that, after Ag 
uptake, undergo maturation, upregulate $\mathrm{MHC}$-class I expression becoming essentially resistant to NK cells. ${ }^{57}$ During the process of maturation, DCs not only upregulate HLA molecules, but also chemokine receptors such as CCR7, and co-stimulatory molecules belonging to the B7 molecular family. ${ }^{58}$ The expression of these molecules is crucial for the subsequent $\mathrm{DC}$ cell migration to $\mathrm{LN}$ and priming of $T$ lymphocytes. It has been suggested that the NK-mediated killing of DCs may serve to keep in check the quality and the quantity of DCs undergoing maturation ('editing' process). ${ }^{18,25}$ According to this view, DCs that fail to express sufficient amounts of $\mathrm{MHC}$ molecules would be removed. Thanks to this mechanism NK cells may prevent the survival of faulty DCs that after expression of CCR7 and migration to lymph nodes, would induce inappropriate, low-affinity, T-cell priming $^{25}$ resulting either in Th2 responses or in a state of tolerization. ${ }^{59}$ In this context, in the absence of NK cells, the in vivo default development pathway of CD4 T cells appears strongly biased toward the acquisition of a Th2 phenotype. ${ }^{60,61}$

The NK cell receptors that are involved in DC recognition and killing are represented by $\mathrm{NKp} 30^{15}$ and DNAM-1. ${ }^{62}$ Indeed blocking of these receptors by specific mAbs was shown to inhibit sharply the NK-mediated killing of immature DCs. In line with these data, NK cells from acute myeloid leukemia (AML) and HIV patients, which frequently express an NKp30 dull phenotype ${ }^{63,64}$ had an impaired ability of killing DCs. ${ }^{65,66}$ Moreover killing of DCs can also be inhibited in the presence of TGF- $\beta$, a cytokine inducing a profound downregulation of the surface expression of NKp30. ${ }^{67}$ On the other hand tryptophan, catabolite L-kynurenine (IDO), although affecting NK cell-mediated killing of tumor cells by downregulating the expression of NKp46 and NKG2D, does not impair NK-mediated DC killing because it has no effect on NKp30 expression. ${ }^{68}$ The importance of DNAM-1 not only as an activating receptor involved in DC killing but also as an adhesion molecule was demonstrated by the finding that NK cells from patients affected by type 1 leukocyte adhesion deficiency (lacking expression of LFA-1) displayed unaltered ability to kill DCs. ${ }^{69}$ The ability of NK cells to kill DCs also involves various HLA-specific inhibitory receptors as demonstrated by the analysis of NK cell clones. In view of these studies it appears that killing of autologous immature DC is confined to NK-cells expressing the HLA-Especific CD94-NKG2A inhibitory receptor but lacking inhibitory KIRs specific for self-HLA-class I alleles. ${ }^{70}$ In line with this finding immature myeloid DC, although displaying a general downregulation of surface HLA class I molecules, are characterized by particularly low levels of surface HLA-E molecules.

\section{NK Cell-Mediated Differentiation of DC}

It has been suggested that, during the early phases of an inflammatory response, the engagement of TLRs by PAMPs may not be confined to NK and DCs but could also involve other cell types, including resident mast cells, ${ }^{71}$ neutrophils, ${ }^{72}$ eosinophils ${ }^{73}$ or PDCs. ${ }^{51}$ It is likely that these cells, through the release of cytokines other than IL12 (e.g. IL4, IFN- $\alpha$ or IL18), could differentially modulate the functional capability of bystander NK and DCs. Indeed it has recently been proposed that the early exposure of NK cells to IL4 could deviate the subsequent adaptive immune response towards the acquisition of a non-Th1 phenotype. ${ }^{74}$ In particular, while short-term NK-cell exposure to IL12 promoted the release of high levels of both IFN- $\gamma$ and TNF- $\alpha$ and the acquisition of cytolytic activity, exposure to IL4 resulted in poor cytokine production and low cytolytic activity. Accordingly, NK cells exposed to IL12 may favor the differentiation/selection of appropriate mature DCs for subsequent Th1 cell priming in lymph nodes. On the contrary, NK cells exposed to IL4 would not exert DC selection, may impair efficient Th1 priming and favor either tolerogenic or Th2-type responses. Another recent study proposed that, in addition to IL12, other cytokines, such as IL18, released by DCs or by macrophages, in response to pathogens, may influence the 'helper' activity of NK cells, ${ }^{75}$ IL18, but not other NK cell-activating cytokines, would promote the development of a unique type of helper NK cells characterized by the $\mathrm{CD} 6^{+} / \mathrm{CD} 83^{+} / \mathrm{CCR} 7^{+} / \mathrm{CD} 25^{+}$phenotype. These IL18-induced NK cells appear to display high migratory responsiveness to LN-produced chemokines, a distinctive ability to support IL12 production by DCs and to promote Th1 responses by CD4 ${ }^{+} \mathrm{T}$ cells (Figure 3 ). Thus it may be possible that not only 'classical' CD56 ${ }^{\text {high }} \mathrm{CD} 16^{-}$but also $\mathrm{CD}^{\text {low }} \mathrm{CD}^{\mathrm{l}}{ }^{+} \mathrm{NK}$ cells (at least under certain conditions) could migrate to lymph nodes. However, CD56 $6^{\text {high }}$ $\mathrm{CD}^{-}{ }^{-} \mathrm{NK}$ cells would reach these sites directly from the blood, whereas CD56 ${ }^{\text {low }} \mathrm{CD} 16^{+}$NK cells would follow a different route that include their activation by IL18 released by APCs encountered within inflamed peripheral tissues. Interestingly, since IL18-induced 'migratory' NK cells, unlike conventional CD56 ${ }^{\text {low }} \mathrm{CD} 16^{+} \mathrm{NK}$ cells, display low cytotoxicity but high cytokine release it is possible that their role within secondary lymphoid tissues may not be different from that of 'resident' CD56 ${ }^{\text {high }}$ CD16 ${ }^{-}$NK cells.

It has also been shown that IL18, released by DC, might play a role during the early phases of innate immune responses by recruiting PDCs, through IL18-receptor expression. In addition, PDC exposed to IL18 may skew the development of adaptive immunity towards Th1 polarization. ${ }^{76}$ The pattern of TLR expression in PDCs is profoundly different from that of DCs. Thus, PDCs do not express TLR1, 2, 3, 4, 5 and 6 but, similar to NK cells, express TLR9, a receptor specific for unmethylated $\mathrm{CpG}$ derived from bacteria or from viruses. ${ }^{77}$ It has been shown that, in the presence of stimulation via TLR9, the NK-PDC interaction results in upregulation of the NK-mediated cytotoxicity against various tumor target cells. In turn, NK cells promote PDC maturation and upregulate their production of IFN- $\alpha$ in response to CpG. ${ }^{22,78}$ Interestingly, while NK cells cannot exert an editing program on PDCs due to the poor susceptibility of these cells to NK-mediated lysis, when co-cultured with TLR9-stimulated PDCs, NK cells acquire lytic activity against immature DCs. Thus, it is possible that cellular interactions occurring between NK and PDCs in response to TLR9 stimulation may influence the maturation and acquisition of functional competence by bystander DCs. These data suggest that a multidirectional PDC-NK-DC crosstalk may deeply affect the outcome of antiviral and anti-tumor immunity by regulating both innate NK cell responses and Th polarization. ${ }^{78}$ 


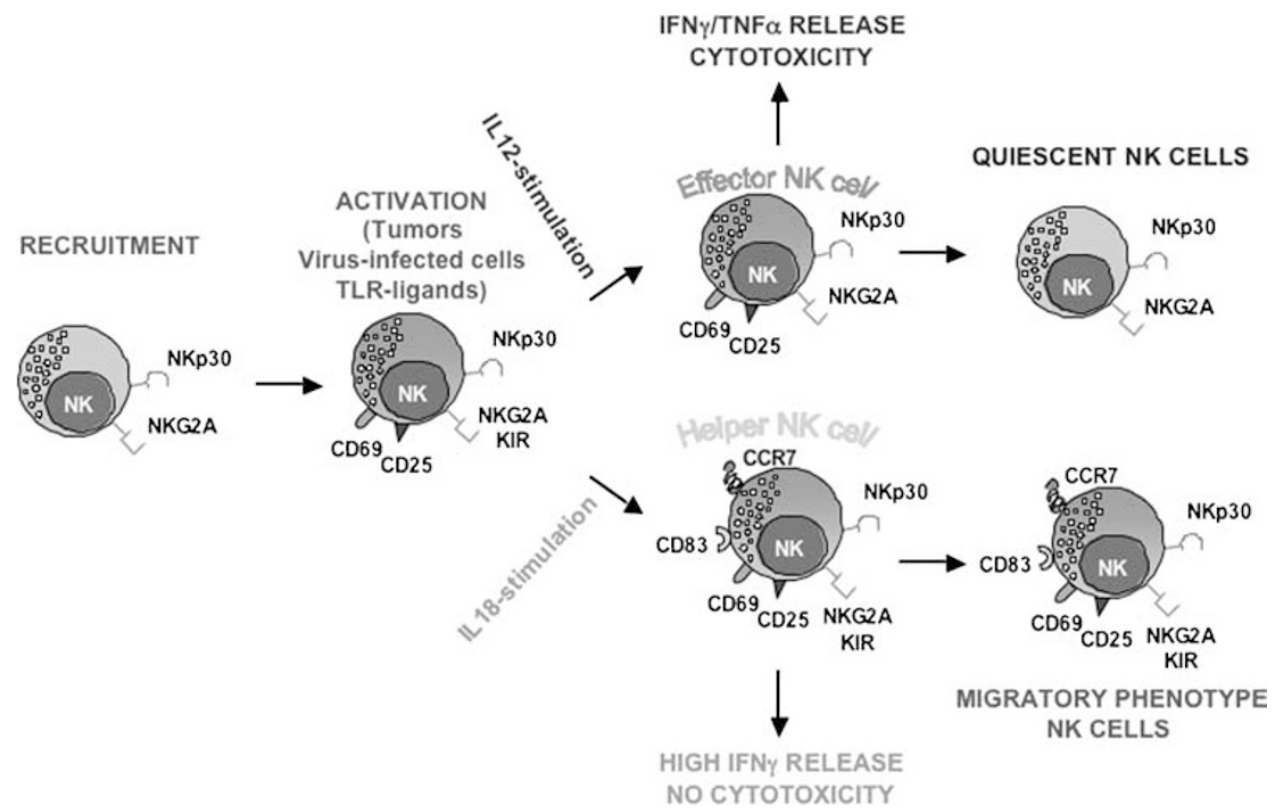

Figure 3 Helper and effector natural killer (NK) cells are generated in inflamed peripheral tissues. CD56 ${ }^{\text {low }} \mathrm{CD} 16^{+} \mathrm{NK}$ cells are recruited to peripheral inflammatory sites in response to chemokine gradients. Then these cells become activated upon encounter with tumors or virus-infected cells that are recognized via different triggering receptors expressed at the NK surface. Alternatively, NK cells may become activated upon encounter with pathogen-derived products that are recognized via TLRs. Once activated NK cells acquire distinct functional characteristics depending upon the prevalence of IL12 versus IL18 available within the inflammatory microenvironment. In the presence of IL12 (released by DCs upon Ag recognition), NK cells acquire the ability to kill those dendritic cells (DCs) that have not been suitably activated by the Ag. These DCs, different from those undergoing appropriate maturation, do not upregulate HLA class I molecules and, similar to immature DCs, would remain susceptible to NK-mediated killing. Meanwhile, the same NK cells release cytokines such as tumor necrosis factor (TNF)- $\alpha$ and interferon (IFN)- $\gamma$ that have been demonstrated to facilitate the progression of pathogenresponsive DCs towards a full maturation. The latter is characterized by a strong upregulation of HLA expression, by the de novo expression of CCR7 and by the upregulation of co-stimulatory molecules such as CD80 and CD86. These mature DCs migrate to secondary lymphoid compartments to promote Th1 polarization. On the other hand, NK cells would remain within the inflamed tissue and, in the absence of further stimulation, may return to their original quiescent status. Alternatively, upon exposure to massive doses of IL18, NK cells may acquire a helper phenotype characterized by strong upregulation of IFN- $\gamma$ release, but poor cytolytic activity. The fate of these NK cells might be different from that of IL12-induced effector NK cells. Indeed IL18-induced helper NK cells by acquiring the expression of surface CCR7 (and CD83) could respond to CCL19/ CCL21 and migrate to secondary lymphoid organs

The molecular interactions regulating the cross talk between NK and monocyte-derived DCs might change at least in part when DCs are subjected to viral infection. In this context a recent study by Draghi et al. ${ }^{79}$ analyzed the impact of influenza-infected human DCs on NK cell activation. It appears that, at variance with uninfected DCs, ${ }^{15,80}$ the ligands for both NKG2D (ULBP) and NKp46 (hemagglutinin) activating receptors are expressed on the surface of infected DCs (Figure 4). Importantly, under these conditions, the use of antibodies against these receptors could inhibit NK cell activation and IFN- $\gamma$ release. Interestingly, the upregulation of NK cell-mediated cytotoxicity induced by infected DCs was mainly dependent on IFN- $\alpha$, whereas IL12 was only necessary for enhancing IFN- $\gamma$ production by NK cells. ${ }^{79}$

\section{Concluding Remarks}

It is becoming clear that many different cell types of the innate immune system are playing a key role during the early phases of infections. These cells interact with each other in inflamed tissues and in secondary lymphoid organs leading to modulation or amplification of different effector mechanisms. Most cellular interactions appear to require direct cell to cell contact to favor the polarized delivery of cytokines, such as IL12, IL4 and IFN- $\alpha$. These are released in response to a large
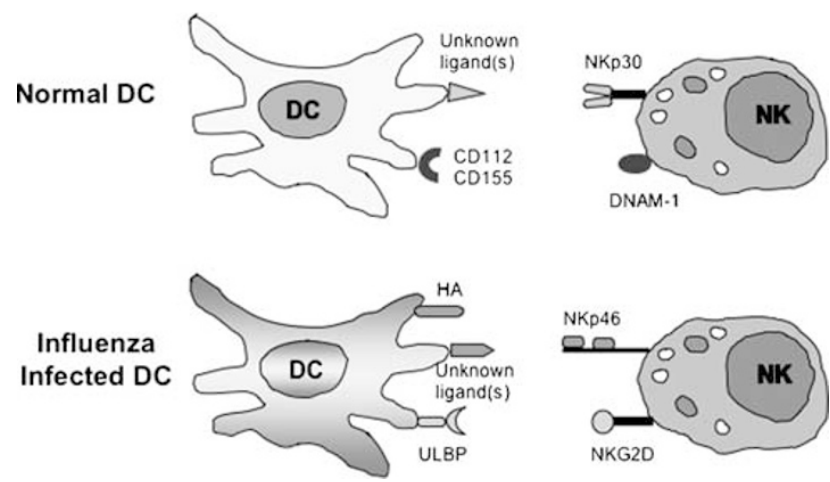

Figure 4 Different receptor-ligand interactions characterize the cross talk between natural killer (NK) cells and virus-infected or non-infected dendritic cells (DCs). The capability of NK cells of killing autologous myeloid immature DCs (iDCs) (but not $\mathrm{mDCs}$ ) is a most remarkable event occurring during the NK-DC cross talk. This effect is based on the capability of NK cells of discriminating between myeloid iDCs (that typically under express HLA-class I molecules) and DCs that, after Ag uptake, upregulate HLA-class I expression while they undergo maturation. The process by which NK cells eliminate iDCs has been shown to initiate with the engagement of the NKp30 and DNAM. 1 activating receptors by ligands expressed on iDCs. Indeed, blocking of NKp30 and DNAM. 1 by specific mAbs sharply inhibited the NK-mediated killing of iDCs. Following influenza infection DCs acquire the expression of ULBP and HA recognized by NKG2D and NKp46 respectively. Accordingly the interaction between NK cells and influenza-infected DCs is inhibited by mAbs specific for these two receptors 
array of microbial products that upon binding to different TLRs can simultaneously activate different effector cells of the innate immunity, including NK cells. The polarizing effect of IL12 and IFN- $\alpha$ released in the microenvironment modulates the functional capability of NK cells that acquire the ability to mediate their editing program. This is leading to the generation of mature DCs that after migration into LN are skewing T-cell priming towards highly polarized Th1 responses. On the contrary, the release of type 2 cytokines including IL4, IL5 and IL13 within the inflammatory microenvironment may deviate the subsequent $\mathrm{T}$ cell priming towards unpolarized or Th2adaptive responses. Thus the outcome of these cellular interactions may have dramatic impact on the quality and strength of downstream adaptive responses. In conclusion, these data suggest that classical innate effector cells such as NK cells can also be viewed as regulatory cells that depending on the cellular interactions and on the type of cytokines released after pathogen invasion play a key role in skewing T-cell priming.

It is likely that understanding of the innate interactions taking place at the interface between innate and adaptive immunity may have a major impact also in designing novel therapeutic approaches against different invading pathogens and, perhaps, tumors.

1. Trinchieri G. Biology of natural killer cells. Adv Immunol 1989; 47: 187-376.

2. Moretta A, Bottino C, Mingari MC, Biassoni R, Moretta L. What is a natural killer cell? Nat Immunol 2002; 3: 6-8.

3. Bottino C, Castriconi R, Moretta L, Moretta A. Cellular ligands of activating NK receptors. Trends Immunol 2005; 26: 221-226.

4. Long EO. Regulation of immune responses through inhibitory receptors. Annu Rev Immunol 1999; 17: 875-904.

5. Moretta A, Bottino C, Vitale M, Pende D, Cantoni C, Mingari MC et al. Activating receptors and coreceptors involved in human natural killer cell-mediated cytolysis. Annu Rev Immunol 2001; 19: 197-223.

6. Moretta A, Bottino C, Vitale M, Pende D, Biassoni R, Mingari MC et al. Receptors for HLA class-I molecules in human natural killer cells. Annu Rev Immunol 1996; 14: 619-648.

7. Lopez-Botet M, Llano M, Navarro F, Bellon T. NK cell recognition of non-classical HLA class I molecules. Semin Immunol 2000; 12: 109-119.

8. Vilches C, Parham P. KIR: diverse, rapidly evolving receptors of innate and adaptive immunity. Annu Rev Immunol 2002; 20: 217-251.

9. Stewart $\mathrm{CA}$, Vivier $\mathrm{E}$, Colonna M. Strategies of natural killer cell recognition and signaling. Curr Top Microbiol Immunol 2006; 298: 1-21.

10. Ljunggren HG, Karre K. In search of the 'missing self': MHC molecules and NK cell recognition. Immunol Today 1990; 11: 237-244.

11. Janeway Jr CA, Medzhitov R. Innate immune recognition. Annu Rev Immunol 2002; 20: 197-216.

12. Fernandez NC, Lozier A, Flament C, Ricciardi-Castagnoli P, Bellet D, Suter M et al. Dendritic cells directly trigger NK cell functions: cross-talk relevant in innate anti-tumor immune responses in vivo. Nat Med 1999; 5: 405-411.

13. Wilson JL, Heffler LC, Charo J, Scheynius A, Bejarano MT, Ljunggren HG. Targeting of human dendritic cells by autologous NK cells. J Immunol 1999; 163: 6365-6370.

14. Carbone E, Terrazzano G, Ruggiero G, Zanzi D, Ottaiano A, Manzo C et al. Recognition of autologous dendritic cells by human NK cells. Eur J Immunol 1999; 29: 4022-4029.

15. Ferlazzo G, Tsang ML, Moretta L, Melioli G, Steinman RM, Munz C. Human dendritic cells activate resting natural killer (NK) cells and are recognized via the NKp30 receptor by activated NK cells. J Exp Med 2002; 195: 343-351.

16. Gerosa F, Baldani-Guerra B, Nisii C, Marchesini V, Carra G, Trinchieri G. Reciprocal activating interaction between natural killer cells and dendritic cells. J Exp Med 2002; 195: 327-333.

17. Piccioli D, Sbrana S, Melandri E, Valiante NM. Contact-dependent stimulation and inhibition of dendritic cells by natural killer cells. J Exp Med 2002; 195: 335-341.

18. Moretta A. Natural killer cells and dendritic cells: rendezvous in abused tissues. Nat Rev Immunol 2002; 2: 957-964.

19. Zitvogel L. Dendritic and natural killer cells cooperate in the control/switch of innate immunity. J Exp Med 2002; 195: F9-14.

20. Cooper MA, Fehniger TA, Fuchs A, Colonna M, Caligiuri MA. NK cell and DC interactions. Trends Immunol 2004; 25: 47-52.
21. Walzer T, Dalod M, Robbins SH, Zitvogel L, Vivier E. Natural-killer cells and dendritic cells: 'l'union fait la force'. Blood 2005; 106: 2252-2258.

22. Gerosa F, Gobbi A, Zorzi P, Burg S, Briere F, Carra G et al. The reciprocal interaction of NK cells with plasmacytoid or myeloid dendritic cells profoundly affects innate resistance functions. J Immunol 2005; 174: 727-734.

23. Romagnani C, Della Chiesa M, Kohler S, Moewes B, Radbruch A, Moretta $L$ et al. Activation of human NK cells by plasmacytoid dendritic cells and its modulation by $C D 4+T$ helper cells and CD4+ CD25hi T regulatory cells. Eur J Immunol 2005; 35: 2452-2458.

24. Marcenaro E, Dondero A, Moretta A. Multi-directional cross-regulation of NK cell function during innate immune responses. Transpl Immunol 2006; 17: 16-19.

25. Moretta A, Marcenaro E, Sivori S, Della Chiesa M, Vitale M, Moretta L. Early liaisons between cells of the innate immune system in inflamed peripheral tissues. Trends Immuno 2005; 26: 668-675.

26. Berke $\mathrm{G}$. The binding and lysis of target cells by cytotoxic lymphocytes: molecular and cellular aspects. Annu Rev Immunol 1994; 12: 735-773.

27. Trambas CM, Griffiths GM. Delivering the kiss of death. Nat Immunol 2003; 4: 399-403.

28. Perussia B. Fc receptors on natural killer cells. Curr Top Microbiol Immunol 1998; 230 63-88.

29. Peters PJ, Borst J, Oorschot V, Fukuda M, Krahenbuhl O, Tschopp J et al. Cytotoxic T lymphocyte granules are secretory lysosomes, containing both perforin and granzymes. J Exp Med 1991; 173: 1099-1109.

30. Alter G, Malenfant JM, Altfeld M. CD107a as a functional marker for the identification of natural killer cell activity. J Immunol Methods 2004; 294: 15-22.

31. Bryceson YT, March ME, Barber DF, Ljunggren HG, Long EO. Cytolytic granule polarization and degranulation controlled by different receptors in resting NK cells. J Exp Med 2005; 202: 1001-1012.

32. Bryceson YT, March ME, Ljunggren HG, Long EO. Activation, coactivation, and costimulation of resting human natural killer cells. Immunol Rev 2006; 214: 73-91.

33. Bryceson YT, March ME, Ljunggren HG, Long EO. Synergy among receptors on resting NK cells for the activation of natural cytotoxicity and cytokine secretion. Blood 2006; 107: 159-166.

34. Moretta A, Biassoni R, Bottino C, Mingari MC, Moretta L. Natural cytotoxicity receptors that trigger human NK-cell-mediated cytolysis. Immunol Today 2000; 21: 228-234.

35. Bottino C, Castriconi R, Pende D, Rivera P, Nanni M, Carnemolla B et al. Identification of PVR (CD155) and Nectin-2 (CD112) as cell surface ligands for the human DNAM-1 (CD226) activating molecule. J Exp Med 2003; 198: 557-567.

36. Reymond N, Imbert AM, Devilard E, Fabre S, Chabannon C, Xerri L et al. DNAM-1 and PVR regulate monocyte migration through endothelial junctions. J Exp Med 2004; 199 : 1331-1341.

37. Campbell JJ, Qin S, Unutmaz D, Soler D, Murphy KE, Hodge MR et al. Unique subpopulations of CD56+ NK and NK-T peripheral blood lymphocytes identified by chemokine receptor expression repertoire. J Immunol 2001; 166: 6477-6482.

38. Cooper MA, Fehniger TA, Caligiuri MA. The biology of human natural killer-cell subsets. Trends Immunol 2001; 22: 633-640.

39. Vitale M, Della Chiesa M, Carlomagno S, Romagnani C, Thiel A, Moretta L et al. The small subset of CD56brightCD16- natural killer cells is selectively responsible for both cell proliferation and interferon-gamma production upon interaction with dendritic cells. Eur $J$ Immunol 2004; 34: 1715-1722.

40. Kawashima D, Oshitani N, Jinno Y, Watanabe K, Nakamura S, Higuchi K et al. Augmented expression of secondary lymphoid tissue chemokine and EBI1 ligand chemokine in Crohn's disease. J Clin Pathol 2005; 58: 1057-1063.

41. Ngo VN, Tang HL, Cyster JG. Epstein-Barr virus-induced molecule 1 ligand chemokine is expressed by dendritic cells in lymphoid tissues and strongly attracts naive $T$ cells and activated B cells. J Exp Med 1998; 188: 181-191.

42. Ferlazzo G, Thomas D, Lin SL, Goodman K, Morandi B, Muller WA et al. The abundant NK cells in human secondary lymphoid tissues require activation to express killer cell Ig-like receptors and become cytolytic. J Immunol 2004; 172: 1455-1462.

43. Fehniger TA, Cooper MA, Nuovo GJ, Cella M, Facchetti F, Colonna M et al. CD56bright natural killer cells are present in human lymph nodes and are activated by $T$ cell-derived IL-2: a potential new link between adaptive and innate immunity. Blood 2003; 101: 3052-3057.

44. Romagnani C, Juelke K, Falco M, Morandi B, D'Agostino A, Costa R et al. CD56brightCD16- killer Ig-like receptor- NK cells display longer telomeres and acquire features of CD56dim NK cells upon activation. J Immunol 2007; 178: 4947-4955.

45. Anfossi N, Andre P, Guia S, Falk CS, Roetynck S, Stewart CA et al. Human NK cell education by inhibitory receptors for MHC class I. Immunity 2006; 25: 331-342.

46. Vermi W, Riboldi E, Wittamer V, Gentili F, Luini W, Marrelli S et al. Role of ChemR23 in directing the migration of myeloid and plasmacytoid dendritic cells to lymphoid organs and inflamed skin. J Exp Med 2005; 201: 509-515.

47. Parolini S, Santoro A, Marcenaro E, Luini W, Massardi L, Facchetti F et al. The role of chemerin in the co-localization of NK and dendritic cell subsets into inflamed tissues. Blood 2007.

48. Buentke E, Heffler LC, Wilson JL, Wallin RP, Lofman C, Chambers BJ et al. Natural killer and dendritic cell contact in lesional atopic dermatitis skin-Malassezia-influenced cell interaction. J Invest Dermatol 2002; 119: 850-857.

49. Trinchieri $\mathrm{G}$. Interleukin-12 and the regulation of innate resistance and adaptive immunity. Nat Rev Immunol 2003; 3: 133-146. 
50. Borg $\mathrm{C}$, Jalil A, Laderach D, Maruyama K, Wakasugi $\mathrm{H}$, Charrier $\mathrm{S}$ et al. NK cell activation by dendritic cells $(D C s)$ requires the formation of a synapse leading to IL-12 polarization in DCs. Blood 2004; 104: 3267-3275.

51. Colonna M, Trinchieri G, Liu YJ. Plasmacytoid dendritic cells in immunity. Nat Immuno 2004; 5: 1219-1226

52. Marshall JS, Jawdat DM. Mast cells in innate immunity. J Allergy Clin Immunol 2004; 114 21-27.

53. Mailliard RB, Son YI, Redlinger R, Coates PT, Giermasz A, Morel PA et al. Dendritic cells mediate NK cell help for Th1 and CTL responses: two-signal requirement for the induction of NK cell helper function. J Immunol 2003; 171: 2366-2373.

54. Mocikat R, Braumuller $\mathrm{H}$, Gumy A, Egeter $\mathrm{O}$, Ziegler $\mathrm{H}$, Reusch $\mathrm{U}$ et al. Natural killer cells activated by $\mathrm{MHC}$ class I(low) targets prime dendritic cells to induce protective CD8T cell responses. Immunity 2003; 19: 561-569.

55. Adam C, King S, Allgeier T, Braumuller H, Luking C, Mysliwietz J et al. DC-NK cell cross talk as a novel CD4+ T-cell-independent pathway for antitumor CTL induction. Blood 2005; 106: 338-344.

56. Sivori S, Falco M, Della Chiesa M, Carlomagno S, Vitale M, Moretta $L$ et al. $C p G$ and double-stranded RNA trigger human NK cells by Toll-like receptors: induction of cytokine release and cytotoxicity against tumors and dendritic cells. Proc Natl Acad Sci USA 2004 101: 10116-10121.

57. Ferlazzo G, Morandi B, D’Agostino A, Meazza R, Melioli G, Moretta A et al. The interaction between NK cells and dendritic cells in bacterial infections results in rapid induction of NK cell activation and in the lysis of uninfected dendritic cells. Eur J Immunol 2003; 33: 306-313.

58. Sallusto $F$, Lanzavecchia A. Mobilizing dendritic cells for tolerance, priming, and chronic inflammation. J Exp Med 1999; 189: 611-614.

59. Langenkamp A, Messi M, Lanzavecchia A, Sallusto F. Kinetics of dendritic cell activation: impact on priming of TH1, TH2 and nonpolarized T cells. Nat Immunol 2000; 1: 311-316.

60. Byrne P, McGuirk P, Todryk S, Mills KH. Depletion of NK cells results in disseminating lethal infection with Bordetella pertussis associated with a reduction of antigen-specific Th1 and enhancement of Th2, but not Tr1 cells. Eur J Immunol 2004; 34: 2579-2588.

61. Coudert JD, Coureau C, Guery JC. Preventing NK cell activation by donor dendritic cells enhances allospecific CD4T cell priming and promotes Th type 2 responses to transplantation antigens. J Immunol 2002; 169: 2979-2987.

62. Pende D, Castriconi R, Romagnani P, Spaggiari GM, Marcenaro S, Dondero A et al. Expression of the DNAM-1 ligands, Nectin-2 (CD112) and poliovirus receptor (CD155), on dendritic cells: relevance for natural killer-dendritic cell interaction. Blood 2006; 107 : 2030-2036.

63. Costello RT, Sivori S, Marcenaro E, Lafage-Pochitaloff M, Mozziconacci MJ, Reviron D et al. Defective expression and function of natural killer cell-triggering receptors in patients with acute myeloid leukemia. Blood 2002; 99: 3661-3667.

64. Mavilio D, Lombardo G, Benjamin J, Kim D, Follman D, Marcenaro E et al. Characterization of CD56-/CD16+ natural killer (NK) cells: a highly dysfunctional NK subset expanded in HIV-infected viremic individuals. Proc Natl Acad Sci USA 2005; 102: 2886-2891.

65. Fauriat C, Moretta A, Olive D, Costello RT. Defective killing of dendritic cells by autologous natural killer cells from acute myeloid leukemia patients. Blood 2005; 106: 2186-2188.
66. Mavilio D, Lombardo G, Kinter A, Fogli M, La Sala A, Ortolano S et al. Characterization of the defective interaction between a subset of natural killer cells and dendritic cells in HIV-1 infection. J Exp Med 2006; 203: 2339-2350.

67. Castriconi R, Cantoni C, Della Chiesa M, Vitale M, Marcenaro E, Conte R et al. Transforming growth factor beta 1 inhibits expression of NKp30 and NKG2D receptors: consequences for the NK-mediated killing of dendritic cells. Proc Natl Acad Sci USA 2003; 100: $4120-4125$

68. Chiesa MD, Carlomagno S, Frumento G, Balsamo M, Cantoni C, Conte R et al. The tryptophan catabolite L-kynurenine inhibits the surface expression of NKp46and NKG2D-activating receptors and regulates NK-cell function. Blood 2006; 108: 4118-4125.

69. Castriconi R, Dondero A, Cantoni C, Della Chiesa M, Prato C, Nanni M et al. Functional characterization of natural killer cells in type I leukocyte adhesion deficiency. Blood 2007 (in press).

70. Della Chiesa M, Vitale M, Carlomagno S, Ferlazzo G, Moretta L, Moretta A. The natural killer cell-mediated killing of autologous dendritic cells is confined to a cell subset expressing CD94/NKG2A, but lacking inhibitory killer Ig-like receptors. Eur J Immunol 2003; 33: 1657-1666.

71. Supajatura V, Ushio H, Nakao A, Akira S, Okumura K, Ra C et al. Differential responses of mast cell Toll-like receptors 2 and 4 in allergy and innate immunity. J Clin Invest 2002; 109: 1351-1359.

72. Bennouna S, Bliss SK, Curiel TJ, Denkers EY. Cross-talk in the innate immune system: neutrophils instruct recruitment and activation of dendritic cells during microbial infection. $\mathrm{J}$ Immunol 2003; 171: 6052-6058.

73. Bjerke T, Gaustadnes M, Nielsen S, Nielsen LP, Schiotz PO, Rudiger N et al. Human blood eosinophils produce and secrete interleukin 4. Respir Med 1996; 90: 271-277.

74. Marcenaro E, Della Chiesa M, Bellora F, Parolini S, Millo R, Moretta L et al. IL-12 or IL-4 prime human NK cells to mediate functionally divergent interactions with dendritic cells or tumors. J Immunol 2005; 174: 3992-3998.

75. Mailliard RB, Alber SM, Shen H, Watkins SC, Kirkwood JM, Herberman RB et al. IL-18induced CD83+CCR7+ NK helper cells. J Exp Med 2005; 202: 941-953.

76. Kaser A, Kaser S, Kaneider NC, Enrich B, Wiedermann CJ, Tilg H. Interleukin-18 attracts plasmacytoid dendritic cells (DC2s) and promotes Th1 induction by DC2s through IL-18 receptor expression. Blood 2004; 103: 648-655.

77. Bauer S, Kirschning CJ, Hacker H, Redecke V, Hausmann S, Akira S et al. Human TLR9 confers responsiveness to bacterial DNA via species-specific $\mathrm{CpG}$ motif recognition. Proc Natl Acad Sci USA 2001; 98: 9237-9242.

78. Della Chiesa M, Romagnani C, Thiel A, Moretta L, Moretta A. Multidirectional interactions are bridging human NK cells with plasmacytoid and monocyte-derived dendritic cells during innate immune responses. Blood 2006; 108: 3851-3858.

79. Draghi M, Pashine A, Sanjanwala B, Gendzekhadze K, Cantoni C, Cosman D et al. NKp46 and NKG2D Recognition of Infected Dendritic Cells Is Necessary for NK Cell Activation in the Human Response to Influenza Infection. J Immunol 2007; 178: 2688-2698.

80. Vitale M, Della Chiesa M, Carlomagno S, Pende D, Arico M, Moretta L et al. NK-dependent DC maturation is mediated by TNFalpha and IFNgamma released upon engagement of the NKp30 triggering receptor. Blood 2005; 106: 566-571. 